\title{
Skill Evaluation of Extended-Range Forecasts of Rainfall and Temperature over the Meteorological Subdivisions of India $\mathscr{A}$
}

\author{
SUSMITHA JOSEPH \\ Indian Institute of Tropical Meteorology, Pune, India \\ A. K. SAHAI \\ Indian Institute of Tropical Meteorology, and India Meteorological Department, Pune, India \\ R. Phani, R. Mandal, A. Dey, And R. Chattopadhyay \\ Indian Institute of Tropical Meteorology, Pune, India \\ S. ABHILASH \\ Cochin University of Science and Technology, Kerala, India
}

(Manuscript received 7 April 2018, in final form 21 November 2018)

\begin{abstract}
Under the National Monsoon Mission Project initiated by the government of India's Ministry of Earth Sciences, an indigenous dynamical ensemble prediction system (EPS) has been developed at the Indian Institute of Tropical Meteorology based on the state-of-the-art Climate Forecast System Model version 2 (CFSv2) coupled model, for extended-range ( $\sim 15-20$ days in advance) prediction. The forecasts are generated for the entire year covering the southwest monsoon, the northeast monsoon, and the summer and winter seasons. As the forecast of rainfall is important during the southwest and northeast monsoon seasons, along with that of the temperature during the summer and winter seasons, the present study documents the deterministic as well as probabilistic skill of the EPS in predicting the results in the respective seasons, over various meteorological subdivisions throughout India, on a pentad-lead time scale. The EPS is found to be skillful in predicting rainfall during the southwest and northeast monsoon seasons, as well as temperature during the summer and winter seasons, across different subdivisions of India. In addition, the EPS is noted to be skillful in predicting selected extremes in rainfall and temperature. This affirms the reliability and usefulness of the present EPS from an operational perspective.
\end{abstract}

\section{Introduction}

The major rainy seasons in India are the southwest monsoon season [June-September (JJAS)] and the northeast monsoon season [October-December (OND)]. Most parts of the country, with the exception of the southeastern portion of the peninsula, experience their heaviest rainfall during JJAS, while the southeast peninsula (e.g., the state of Tamil Nadu) receives

Supplemental information related to this paper is available at the Journals Online website: https://doi.org/10.1175/WAF-D-180055.s1.

Corresponding author: Dr. A. K. Sahai, sahai@tropmet.res.in maximum rainfall during OND. During April-June (AMJ), the northwestern, central, and eastern parts of the country experience periodic heat waves. Most of these regions experience occasional cold waves during November-February (NDJF). The rainfall during the southwest (northeast) monsoon season and the extreme temperatures during AMJ (NDJF) are generally associated with larger-scale meteorological features and, thus, are potentially predictable with extended lead time (i.e., 15-20 days in advance).

Extended-range predictions of rainfall and temperature are of great importance due to their widespread applications in the agriculture, water management, urban planning, energy, tourism, and health sectors, and in turn these predictions are beneficial to policy makers. 
TABLE 1. List of the meteorological subdivisions of India.

\begin{tabular}{lll}
\hline \hline 1) Andaman and Nicobar Islands & 2) Arunachal Pradesh & 3) Assam and Meghalaya \\
4) Nagaland, Manipur, Mizoram, and Tripura & 5) Sub-Himalayan western Bengal and Sikkim & 6) Gangetic western Bengal \\
7) Orissa & 8) Jharkhand & 9) Bihar \\
10) East Uttar Pradesh & 11) West Uttar Pradesh & 12) Uttaranchal \\
13) Haryana, Chandigarh, and Delhi & 14) Punjab & 15) Himachal Pradesh \\
16) Jammu and Kashmir & 17) West Rajasthan & 18) East Rajasthan \\
19) West Madhya Pradesh & 20) East Madhya Pradesh & 21) Gujarat \\
22) Saurashtra, Kuch, and Diu & 23) Konkan and Goa & 24) Madhya Maharashtra \\
25) Marathawada & 26) Vidharbha & 27) Chattisgarh \\
28) Coastal Andhra Pradesh & 29) Telengana & 30) Rayalaseema \\
31) Tamil Nadu and Pondicherry & 32) Coastal Karnataka & 33) Northern interior Karnataka \\
34) South interior Karnataka & 35) Kerala & 36) Lakshadweep \\
\hline
\end{tabular}

Under the National Monsoon Mission (http://www. tropmet.res.in/monsoon/), the Indian Institute of Tropical Meteorology has indigenously developed an ensemble prediction system (EPS) for extended-range prediction (Abhilash et al. 2014c), based on the Climate Forecast System version 2 (CFSv2) of the National Centers for Environmental Prediction (NCEP). The current EPS is a mutimodel ensemble (MME) that combines the coupled model CFS at two resolutions-T126 $(\sim 100 \mathrm{~km})$ and T382 ( $\sim 38 \mathrm{~km})$-along with the atmospheric component (GFS) forced with the bias-corrected sea surface temperature (SST) from CFS, at both resolutions. In our multimodel setup, the coupled model CFS at both T126 and T382 resolutions uses the simplified ArakawaSchubert (Pan and Wu 1995) scheme for convective parameterization, whereas the atmospheric model, GFS, uses the new SAS scheme (Han and Pan 2011). Thus, the CFS-based Grand EPS (CGEPS) MME has four variants of the same model having diversity in its physics.

The EPS generates 45-day forecasts at 5-day intervals, beginning on 1 January of each year. Since our focus is on the extended range, the forecasts are being generated for 5-day means such as pentad 1 (P1; day 1-5 average), pentad 2 (P2; day 6-10 average), pentad 3 (P3; day 11-15 average), and pentad 4 ( $\mathrm{P} 4$; day 16-20 average). The main forecast products are rainfall and temperature. Since the forecast of rainfall is important during the southwest and northeast monsoon seasons, along with that of temperature during the summer and winter seasons, we document the skill of the EPS in predicting these during the respective seasons.

As has been documented by earlier studies (Abhilash et al. 2014a,b,c; Abhilash et al. 2015a,b; Sahai et al. 2013, 2015a,b), the CGEPS MME as well as its individual contributing models have reasonable skill in predicting the JJAS rainfall over various homogenous regions throughout India [viz., central India, the monsoon zone of India (Rajeevan et al. 2010); northeast India, northwest India, and the south peninsula]. The skill of the
EPS in predicting extreme rainfall events during JJAS has also been reported by Joseph et al. (2015). Since there is an increasing demand from the user community for forecasts on smaller spatial scales, it is essential to assess the extended-range prediction skill of the EPS over different meteorological subdivisions of India (mentioned in Table 1 and shown in Fig. 1), so as to understand the confidence level in utilizing the forecasts over these regions.

The skill of dynamical forecast products on subdivisional scales has been documented in the literature (Saseendran et al. 2002; Mohanty et al. 2013; Pattanaik 2014). Saseendran et al. (2002) examined the skill of the National Centre for the Medium Range Weather Forecasting T80 spectral model in predicting the weekly cumulative rainfall over the different subdivisions, during the southwest monsoons of 1994-99. Mohanty et al. (2013) and Pattanaik (2014) analyzed the skill of the extended-range rainfall forecasts during the southwest monsoon season. Mohanty et al. (2013) attempted to predict monsoon rainfall (both monthly and seasonal) at extended-range time scales, while Pattanaik (2014) analyzed the skill of weekly extended-range forecasts. However, both of these were case studies and examined only one monsoon season. Nevertheless, no detailed study is available on the skill evaluation of extendedrange rainfall and temperature forecasts for different seasons on subdivisional scales. Therefore, to the best of the authors' knowledge, the present study is a first-of-itskind attempt in this regard.

\section{Data and methodology}

\section{a. Data}

As mentioned earlier, this study uses the extendedrange forecasts from the MME utilizing the CGEPS (Abhilash et al. 2015a,b), which integrates the CFS and its stand-alone atmospheric component (i.e., GFS) forced with bias-corrected CFS-forecasted SST (hereafter GFSbc) 


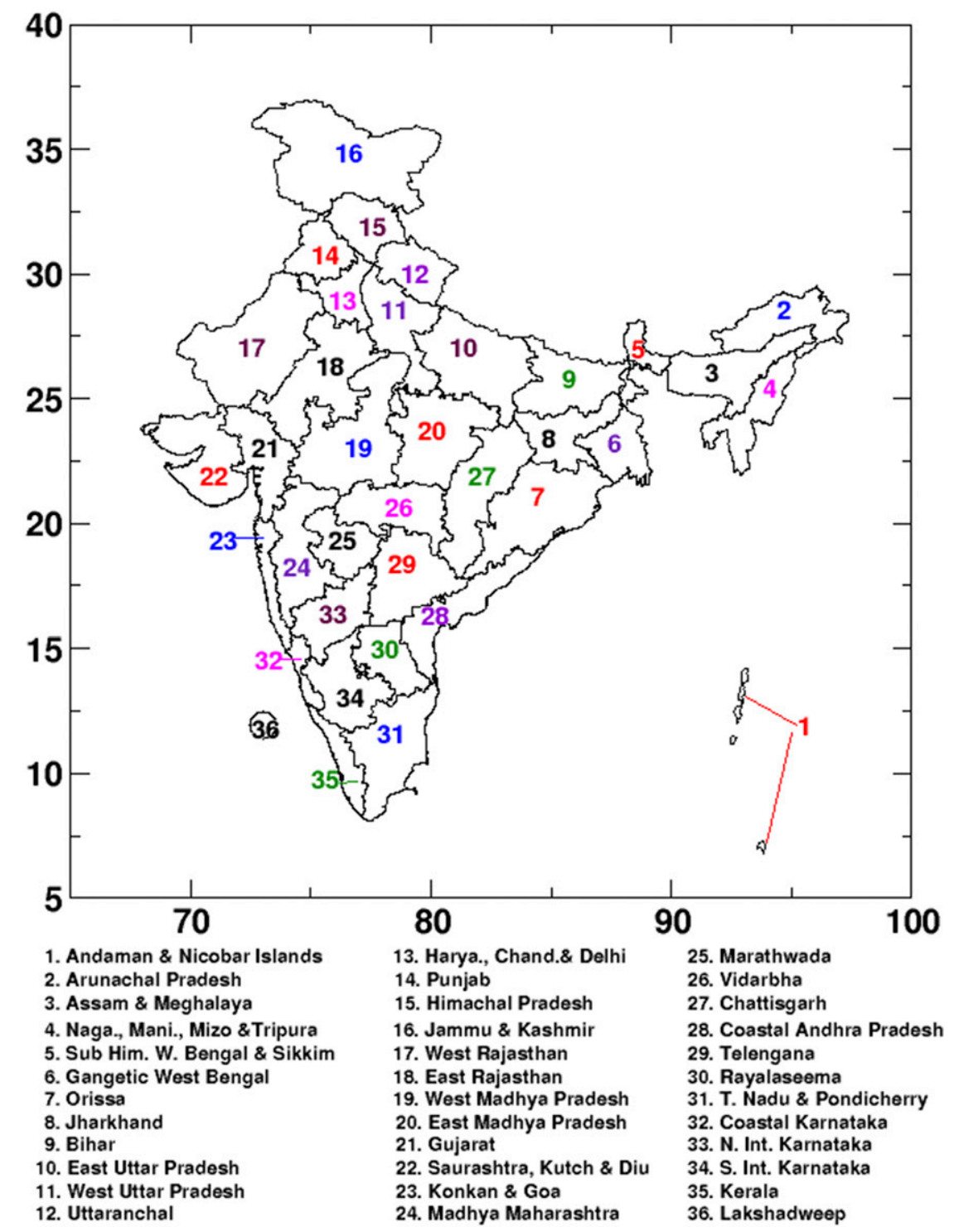

FIG. 1. Meteorological subdivisions of India, as mentioned in Table 1.

at T126 and T382 horizontal resolutions. Detailed skill analysis of the CGEPS MME and its advantages are available from Abhilash et al. (2015a). Real-time implementation of this system and its performance during the 2014 monsoon season can be found in Sahai et al. (2015b). To give equal weights to all models and to add more diversity, the CGEPS has a total of 44 ensemble members with 11 members each from CFST126, CFST382, GFSbcT126, and GFSbcT382 for the extendedrange predictions. The initial conditions have been prepared from a coupled data assimilation system (CDAS) with T574L64 resolution atmospheric assimilation and MOM4-based oceanic assimilation, which is a real-time extension of the CFS Reanalysis (CFSR; Saha et al. 2014).
The hindcast runs are available from 2001 to 2010. For verification purposes, we use the following: gridded rainfall data from the India Meteorological Department (IMD) at $1^{\circ} \times 1^{\circ}$ resolution (Rajeevan et al. 2006) and the maximum and minimum temperature dataset from IMD at $1^{\circ} \times 1^{\circ}$ resolution (Srivastava et al. 2008). Both rainfall and temperature datasets cover Indian land points only.

\section{b. Methodology}

The present study uses different skill scores such as the anomaly correlation coefficient (ACC), root-mean skill score (RMSS), signal-to-noise ratio [SNR; as one of the measures of predictability and has been used in 
previous studies such as in Abhilash et al. (2014b)], Brier skill score (BSS), and area under the relative operative characteristic curve (ROC AUC) skill score to assess the skill of the MME. The first three skill scores are applied to deterministic forecasts, whereas the last two are applied to probabilistic forecasts.

Before calculating the skill scores, except SNR, the forecast values corresponding to a particular pentad lead were pooled together (e.g., all the first pentad forecasts are pooled, all the second pentad forecasts are pooled, and so on). Then, the total number of pentads pertaining to a particular season are considered. For example, if we are calculating the skill scores for the JJAS season, we have a sample of 24 pentads each for the 10 -yr hindcast period, totaling 24 pentads $\times 10$ years $=240$ forecasts, for each pentad lead. In addition, the climatology for defining anomalies has been calculated as the simple average of each variable, for each 5-day period of the hindcast period. The observed climatology is calculated for each of the 24 pentads separately using 10 observed values of the 10 -yr hindcast period. A similar method is used for P1-P4-lead ensemble mean forecasts.

The probabilistic skill scores, BSS and ROC AUC, are calculated for three categories: above normal, near normal, and below normal. The observed tercile categories are defined based on the observed distribution for each pentad during the $10-\mathrm{yr}$ hindcast period. On the other hand, the model forecasted tercile categories are based on the distribution of the ensemble members during the 10-yr hindcast period, for each pentad.

\section{1) Predictability}

The limit of the potential predictability (Shukla and Gutzler 1983) is generally considered to be the lead time at which the SNR becomes less than one. The signal is defined as the standard deviation of ensemble mean forecasts valid at the same forecast lead time, while noise is given as the standard deviation of the ensemble members from the ensemble mean forecast:

$$
\mathrm{SNR}=\frac{\text { Signal }}{\text { Noise }}
$$

\section{2) ANOMAly CORRELATION COEFFiCIENT (ACC)}

The ACC is a common verification metric used to evaluate deterministic extended-range forecasts and is used to identify similarities in the patterns of departures from the climatological mean field (Wilks 2011). If the variation pattern of the forecast anomalies is perfectly coincident with that of the anomalies of the verifying value, ACC will take the maximum value of 1 . Conversely, if the variation pattern is completely reversed, ACC takes the minimum value of -1 .
The ACC is defined as

$$
\mathrm{ACC}=\frac{\sum_{i=1}^{n} \frac{1}{n}\left(f_{i}-\bar{f}\right)\left(o_{i}-\bar{o}\right)}{\sqrt{\sum_{i=1}^{n} \frac{1}{n}\left(f_{i}-\bar{f}\right)^{2} \sum_{i=1}^{n} \frac{1}{n}\left(o_{i}-\bar{o}\right)^{2}}},
$$

where $n$ is the number of samples, $\left(f_{i}-\bar{f}\right)$ is the forecasted anomaly from its own climatology, and $\left(o_{i}-\bar{o}\right)$ is the observed anomaly from its own climatology.

The significance of the ACC values has been calculated based on a Student's $t$ test (Wilks 2011).

\section{3) RoOT-MEAN SKILL SCORE}

The RMSS is essentially the root-mean-square error (RMSE) of the forecasts compared to the RMSE of the climatology (i.e., standard deviation). This metric is applicable to deterministic forecasts alone. Closer-tounity values are indicative of better skill of the forecasts, and any value greater than zero represents a forecast better than climatology.

RMSS can be expressed as

$$
\mathrm{RMSS}=1-\frac{\sqrt{\frac{1}{n} \sum_{i=1}^{n}\left(f_{i}-o_{i}\right)^{2}}}{\sqrt{\frac{1}{n-1} \sum_{i=1}^{n}\left(o_{i}-\bar{o}\right)^{2}}}
$$

\section{4) BRIER SKILL SCORE}

BSS measures the relative skill of probabilistic forecasts compared to a standard or climatological or persistence forecast (Wilks 2011). BSS can be expressed as

$$
\mathrm{BSS}=1-\frac{\mathrm{BS}}{\mathrm{BS}_{\mathrm{ref}}}
$$

where $\mathrm{BS}=(1 / n) \sum_{k=1}^{n}\left(f_{k}-o_{k}\right)^{2}$ is the Brier score that averages the squared differences between pairs of forecast probabilities and the subsequent observations.

A positive value of BSS refers to a forecast that is better than climatology and hence is considered to be skillful. BSS has a negative value if the forecast error is more than that of the climatological forecast.

\section{5) RELATIVE OPERATIVE CHARACTERISTIC AREA}

The ROC diagram represents the ability of a set of probabilistic forecasts to discriminate a dichotomous event, relating the hit rate (HR) and the false alarm rate (FAR) (Kharin and Zwiers 2003). HR is defined as the proportion of occurrences, when both the observed rainfall and the forecasted rainfall are in the same 
category. Similarly, FAR is defined as the proportion of nonoccurrences (i.e., when forecasted rainfall is not in the observed category). A sample ROC diagram is shown in Fig. S1 in the online supplemental material. In a ROC curve, the closer clustering of probability values indicates less spread among the ensemble members. A ROC curve that lies along the diagonal HR = FAR line (dotted line in Fig. S1) indicates no skill; a curve that sweeps out the maximal area, as far toward the top-left corner as possible, indicates maximal skill (Hamill and Juras 2006). The ROC is commonly summarized through the integrated area under the ROC curve (i.e., the AUC of ROC). The AUC of ROC can be used in the calculation of the probabilistic skill. For a perfect forecast, this area is 1.0, and forecasts that are random draws from climatology have a value equaling 0.5 . Therefore, values greater than 0.5 (area above the dotted line in Fig. S1) are considered to be skillful.

\section{Skill over meteorological subdivisions of India}

Here, we discuss the seasonal skill of the EPS over the meteorological subdivisions over all of India (shown in Fig. 1), except for the offshore islands (Andaman and Nicobar Islands and Lakshadweep).

\section{a. Limit of predictability in the four seasons}

Before discussing the seasonal skill in the following subsections, it is important to understand the limits of predictability (lead time when signal equals noise) of the important meteorological variables during the four seasons. Figures $2 \mathrm{a}$ and $2 \mathrm{~b}$ correspond to the predictability limits of JJAS and OND rainfall, while Figs. $2 \mathrm{c}$ and $2 \mathrm{~d}$ represent that of the maximum temperature during AMJ and the minimum temperature during NDJF.

It is found that the central, eastern, and northeastern parts of the country (which are mainly affected by lows and depressions) have predictability of only 6-9 days for JJAS rainfall (Fig. 2a). The maximum predictability (of 12-15 days) is evident over some parts of northwest India, coastal Karnataka, and the Konkan and Goa regions. The difference in the predictability over these regions could be attributed to the fact that the rainfall over the eastern parts of the country are contributed from synoptic systems with less predictability, while the western parts are affected by the intraseasonal oscillations with comparatively larger predictability.

The northeast monsoon season is the main rain-giving season for southeast peninsular India, especially for the state of Tamil Nadu. According to Kripalani and Kumar (2004), the subdivisions affected by the northeast monsoon are Kerala, Tamil Nadu, northern interior Karnataka, southern interior Karnataka, coastal Karnataka, Rayalaseema, and coastal Andhra Pradesh. Therefore, we have plotted all the skill scores over only those regions. Figure $2 \mathrm{~b}$ indicates that the predictability of OND rainfall is more than 12 days for all the relevant subdivisions. The predictability is maximum over northern interior Karnataka, with decreasing values over coastal and southern interior Karnataka, followed by Rayalaseema and coastal Andhra Pradesh, and then Kerala and Tamil Nadu.

India experiences heat waves during AMJ, especially over the northwestern, central, and southeast regions of the country. Maximum temperature is the most important meteorological variable that determines the severity of heat waves. Therefore, this study examines the hindcast (2001-10) skill of the CGEPS MME in predicting maximum temperature during all pentads of AMJ. The predictability limit for AMJ maximum temperature (Fig. 2c) indicates that, for most parts of the country, predictability exceeds 16 days, while over central India, the predictability is $>30$ days.

During the winter season, the northern parts of the country experience cold waves, due to the passage of weather disturbances in the midlatitude westerlies. At times, the western disturbances even move up toward central India. Minimum temperature is the main meteorological variable that determines the severity of cold waves and hence in this study we examine the prediction skill of minimum temperature for all pentads during NDJF of the hindcast period 2001-10. The predictability of minimum temperature during NDJF (Fig. 2d) is on the higher side ( $>30$ days) over most parts of the country.

\section{b. Deterministic and probabilistic prediction skill of rainfall during JJAS}

The pentad-wise (P1-P4) ACC for the hindcast period for all pentads during JJAS is shown in Figs. 3a-d. Correlations significant at the $99.9 \%$ significance level are only shaded in the figure. Figure 3 clearly shows that the MME has considerable skill over most parts of the country until P3 lead and reasonable skill at P4 lead. RMSS values greater than zero are considered to be skillful and the MME has reasonable RMSS results during the first two pentads (Figs. 3e-h). Even at P4 lead, some subdivisions over western parts of the country show reasonable skill.

Figure 4 illustrates the probabilistic skill scores (BSS and AUC) for the above normal (AN) and below normal (BN) categories of JJAS rainfall. Figures $4 a-d$ represent the BSSs for the above normal category, while Figs. 4e-h illustrate that of the below normal category. It is clear from Fig. 4 that most parts of the country have 

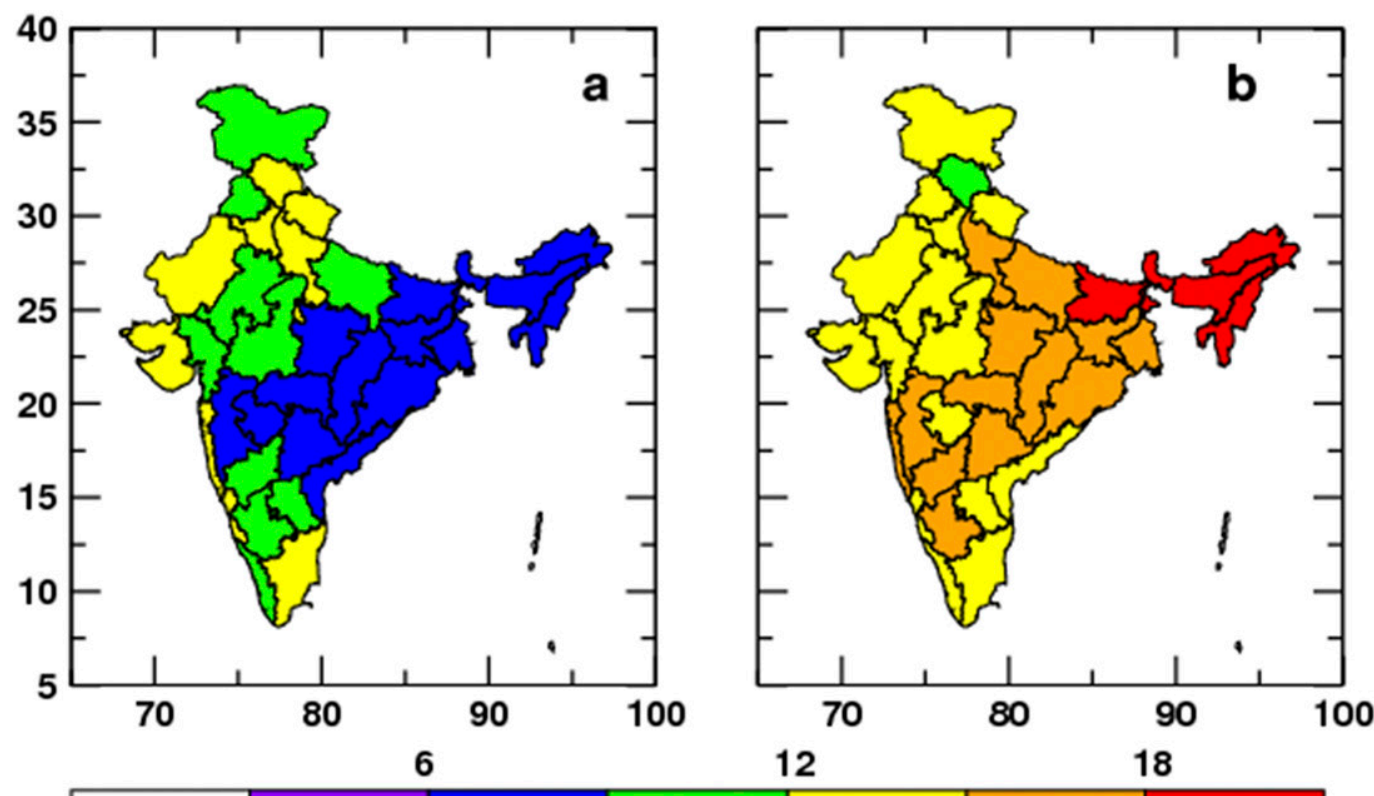

3

9

15
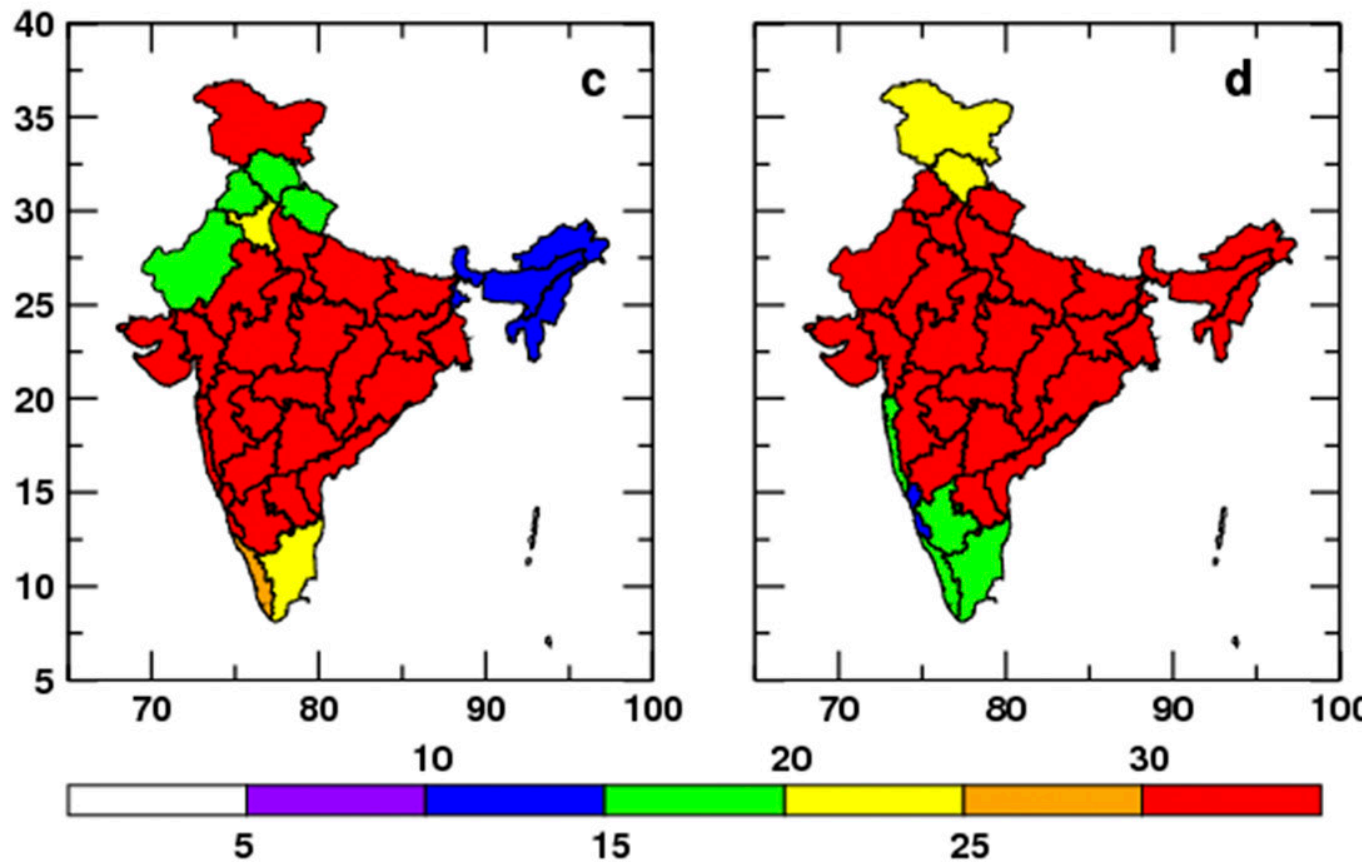

FIG. 2. Limit of predictability (day when signal equals noise) of (a) JJAS rainfall, (b) OND rainfall, (c) AMJ maximum temperature, and (d) NDJF minimum temperature.

better BSSs until P3 lead. Until P4 lead, the northwestern and central parts show reasonable BSSs for both the above normal and below normal categories. The subdivisions over the west coast exhibit skill that exceeds climatology through P3 lead time. The AUC for the above normal and below normal categories for the
JJAS rainfall is shown in Fig. 5. As mentioned in section $2 b$, values greater than 0.5 designate useful skill. It is interesting to note that the MME has valuable skill for both categories until P4 lead, with an exception over the Nagaland-Manipur-MizoramTripura region at $\mathrm{P} 4$ lead. 

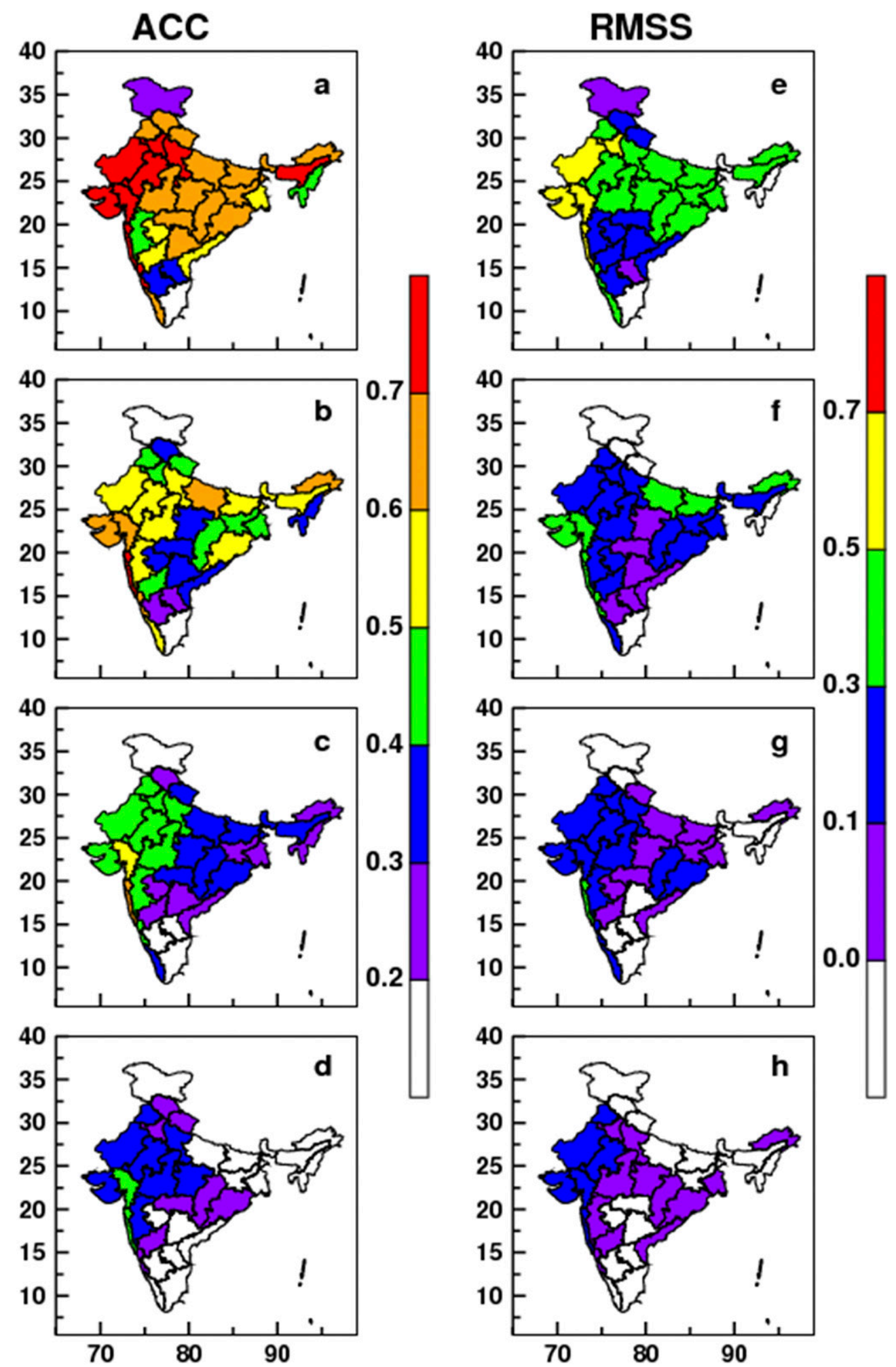

FIG. 3. Pentad-wise (P1-P4) (a)-(d) ACC and (e)-(h) RMSS of JJAS rainfall for all pentads during 2001-10. 

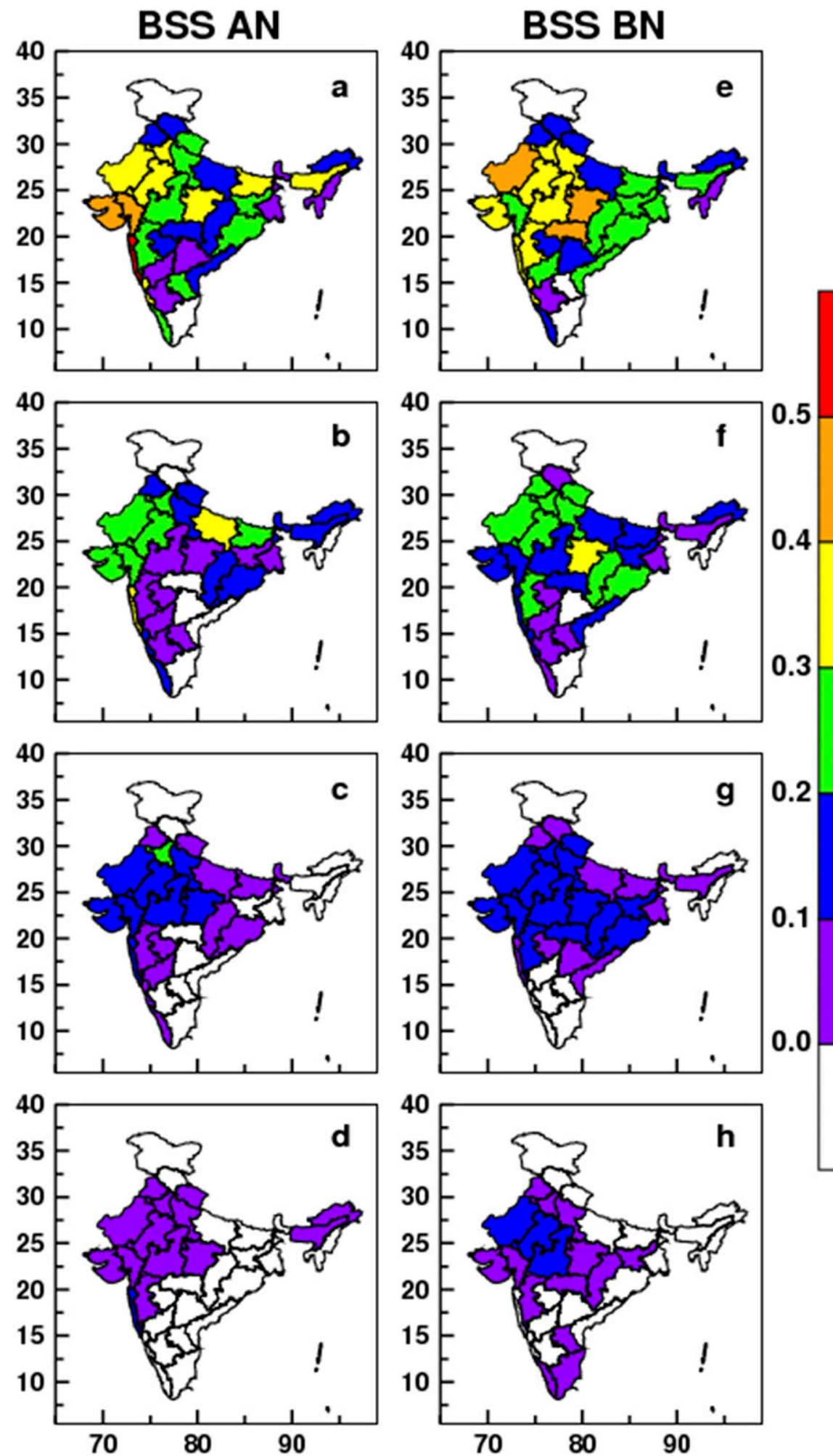

FIG. 4. Pentad-wise (P1-P4) BSS of JJAS rainfall in the (a)-(d) AN and (e)-(h) BN categories for all pentads during 2001-10. 

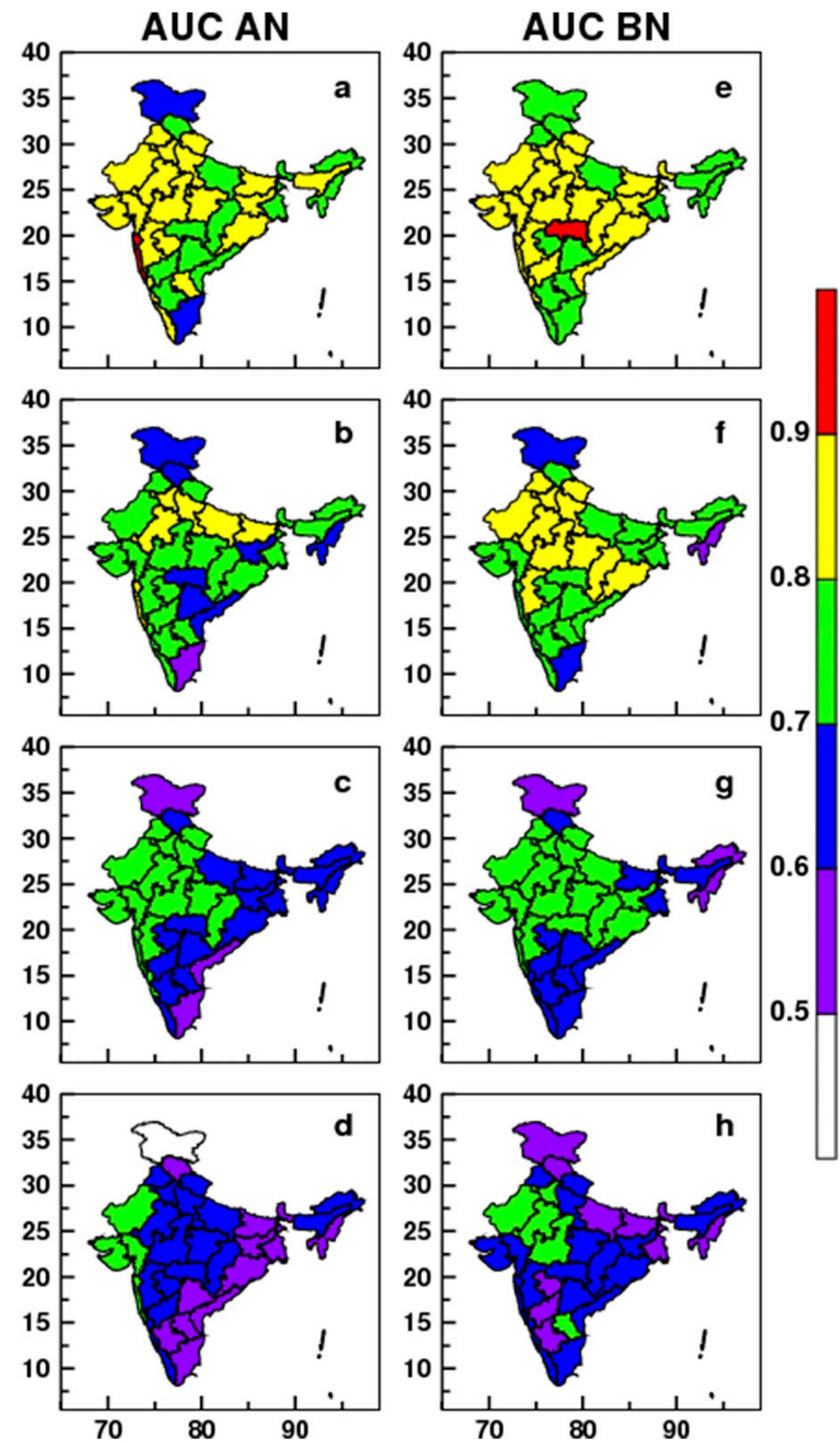

FIG. 5. Pentad-wise (P1-P4) AUC of JJAS rainfall in the (a)-(d) AN and (e)-(h) BN categories for all pentads during 2001-10. 


\section{c. Deterministic and probabilistic prediction skill of rainfall during $O N D$}

The ACC and RMSS results for northeast monsoon rainfall during OND are revealed in Fig. 6. It is seen that the CGEPS MME has significant correlations over all relevant subdivisions up to P3 lead (Figs. 6a-d). During P4 lead, the ACC becomes insignificant for northern interior Karnataka, Rayalaseema, and coastal Andhra Pradesh. The RMSS values are skillful over the relevant subdivisions for the first two pentads (Figs. 6e-h). The forecasts are skillful over Kerala, Tamil Nadu, and coastal Karnataka until P4 lead.

The BSS values for the above normal and below normal categories of OND rainfall are plotted in Fig. 7. Skillful BSS for above normal for all pentad leads is observed only over Kerala (Figs. 7a-d), while for the below normal category, it is over northern interior Karnataka and coastal Andhra Pradesh (Figs. 7e-h). For the below normal category, all regions possess skillful BSSs until P3 lead. The AUC values for the above normal and below normal categories show acceptable skill for all pentad leads (Fig. 8), which is a very good indication that the MME is capable of predicting the extremes of OND rainfall.

\section{d. Deterministic and probabilistic prediction skill of maximum temperature during $A M J$}

Figure 9 shows the ACC and RMSS results of maximum temperature during AMJ. It is remarkable that the MME has significant values of ACC up to P4 lead over almost all of the country, except over the northeastern parts and the Jammu and Kashmir regions (Figs. 9a-d, left). The regions that experience heat wave conditions have remarkable ACCs during all four pentad leads, which gives us the confidence to use the MME for heat wave predictions. The RMSS values also demonstrate similar results (Figs. 9e-h, right). At P1 lead, the RMSS reach even up to 0.8 over the northwestern parts of the country. However, over Orissa where severe heat wave conditions occur, the RMSS is only useful until P2 lead.

As higher than normal temperatures are seminal for the prediction of heat waves, we examine the probabilistic prediction skill of maximum temperature for the above normal category alone in Fig. 10. The BSS for the above normal category is shown in Figs. 10a-d. It is found that the heat wave region (i.e., northwestern, central, and southeastern parts) has useful skill up to P3 lead. For northwestern and central India, the skill extends until P4 lead. The AUC plotted in Figs. 10e-h affirms the usefulness of the maximum temperature forecasts over the heat-wave-prone subdivisions until P4 lead.

\section{e. Deterministic and probabilistic prediction skill of minimum temperature during NDJF}

Figures 11a-d portray the ACC for minimum temperature during NDJF, and it is clear from the figure that the correlations are significant all over the country until P3 lead. At P4 lead, the ACC values decrease over Konkan and Goa, Telengana, northern interior Karnataka, Orissa, and Chattisgarh. However, this is unimportant as these regions are generally not affected by cold waves. Compared to other seasons, skillful RMSS values are noticed over many parts of the country until P4 lead during NDJF (Figs. 11e-h). At P1 lead, the RMSS values of more than 0.5 are noted almost all over the country. This is indicative of the significant skill of the CGEPS MME in predicting the minimum temperature during NDJF.

Since cold waves are related to lower than normal temperatures, the probabilistic skill scores (i.e., BSS and AUC) are evaluated for the below normal category alone in Fig. 12. The northern subdivisions over the country that are generally affected by cold waves have useful BSSs for the below normal category up to P3 lead (Figs. 12a-d). The skill becomes negligible at $\mathrm{P} 4$ lead. The AUC results for the below normal category are competent up to P4 lead (Figs. 12e-h).

\section{f. Skill of MME in predicting extremes in rainfall and temperature}

The previous subsections discussed the general deterministic and probabilistic skill of the MME in predicting the rainfall and temperature during different seasons. Here, we examine the ability of the MME in predicting extremes in rainfall and temperature during the relevant seasons. From each season, we have randomly selected one extreme spell. The general skill of the MME in predicting the extremes is discussed in section S2 in the online supplement. The observed probability for a particular extreme spell is calculated based on the number of days that satisfy a particular threshold value during the entire duration of the spell; whereas for the MME-predicted probability, we consider the number of days times the number of ensemble members that satisfy the same threshold value during the spell.

Figure 13 depicts the extremes of rainfall during JJAS and OND seasons. The extremes in rainfall are manifested as dry and wet spells, which are referred to as "break" and "active" spells during the season. For the JJAS season, a break spell refers to a spell of little or no rain over most parts of the country, whereas an active spell indicates a spell with a good amount of rainfall over most parts of the country. During 17-23 June 2009, 

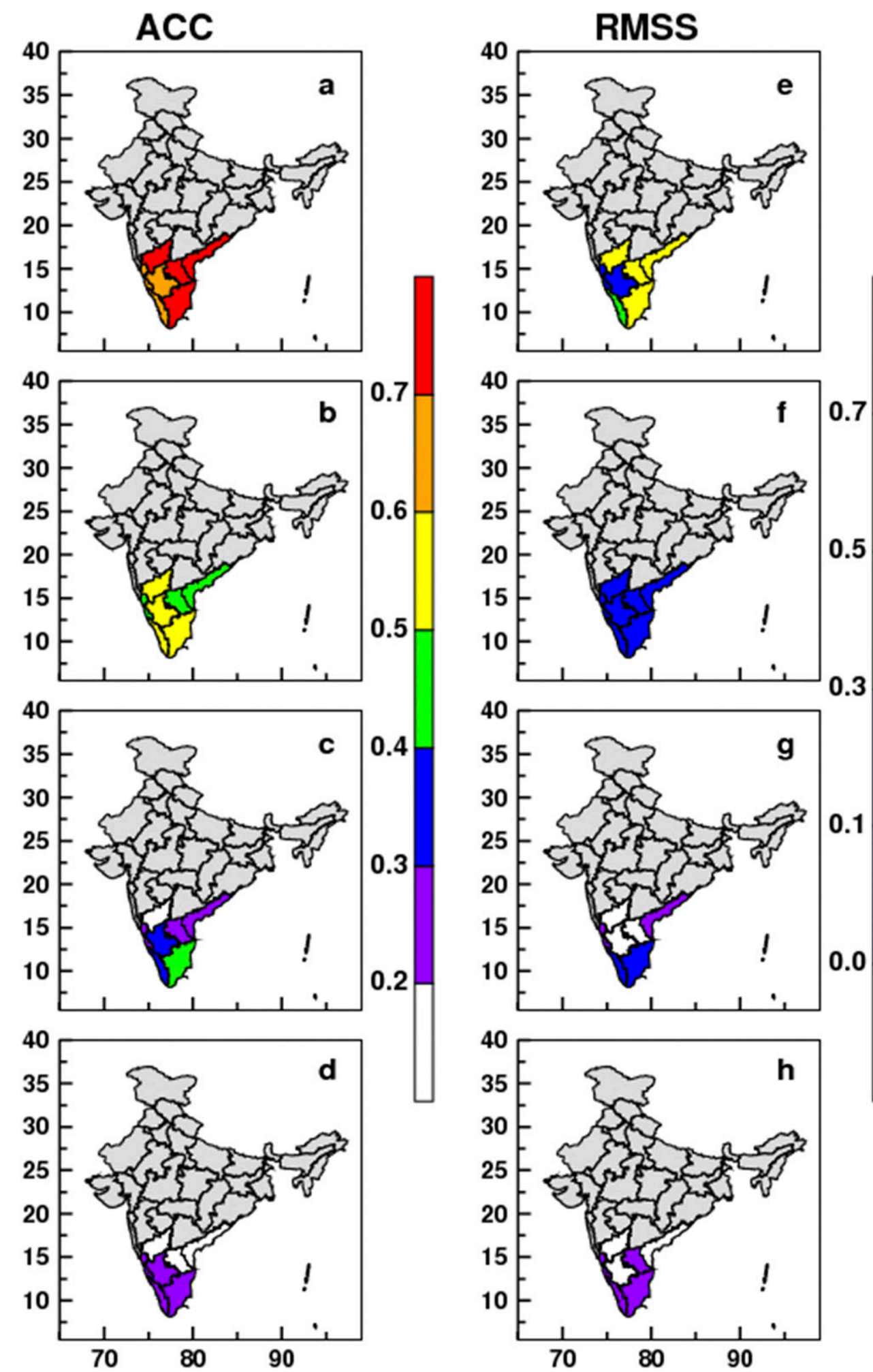

FIG. 6. As in Fig. 3, but for OND rainfall. Here, the subdivisions that are not affected by OND monsoons are shaded in grayscale. 

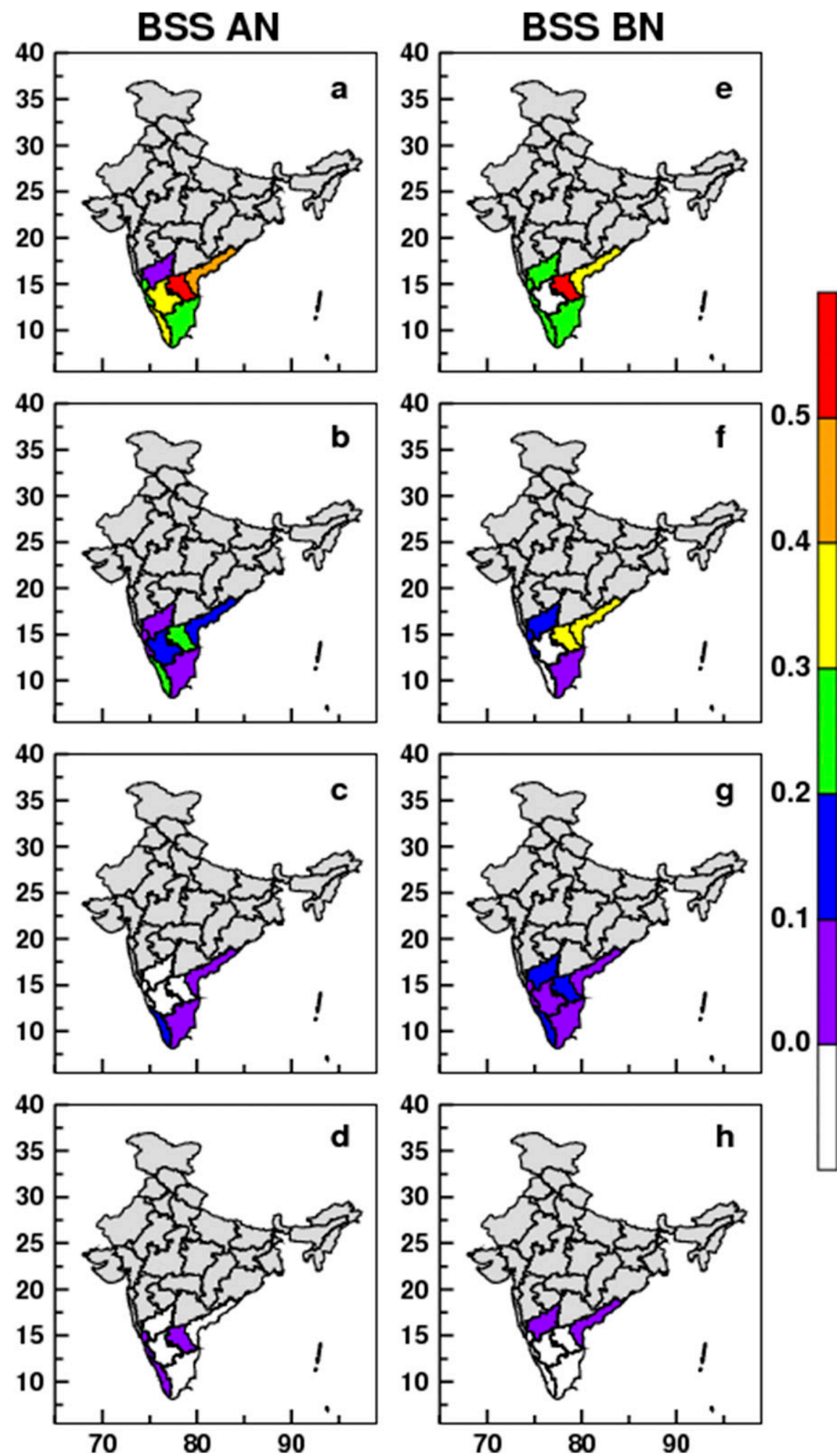

FIG. 7. As in Fig. 4, but for OND rainfall. Here, the subdivisions that are not affected by OND monsoons are shaded in grayscale. 

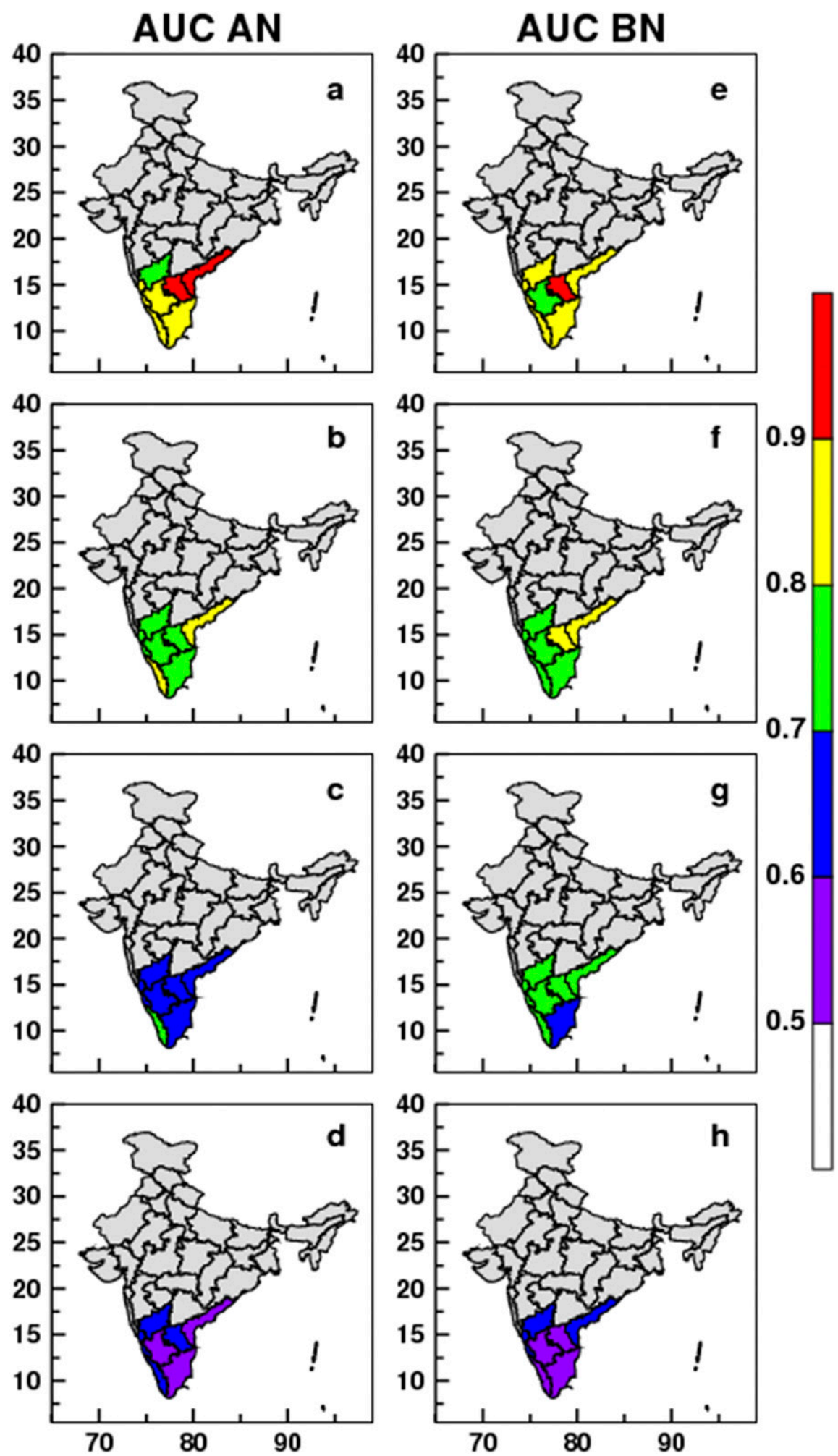

FIG. 8. As in Fig. 5, but for OND rainfall. Here, the subdivisions that are not affected by OND monsoons are shaded in grayscale. 

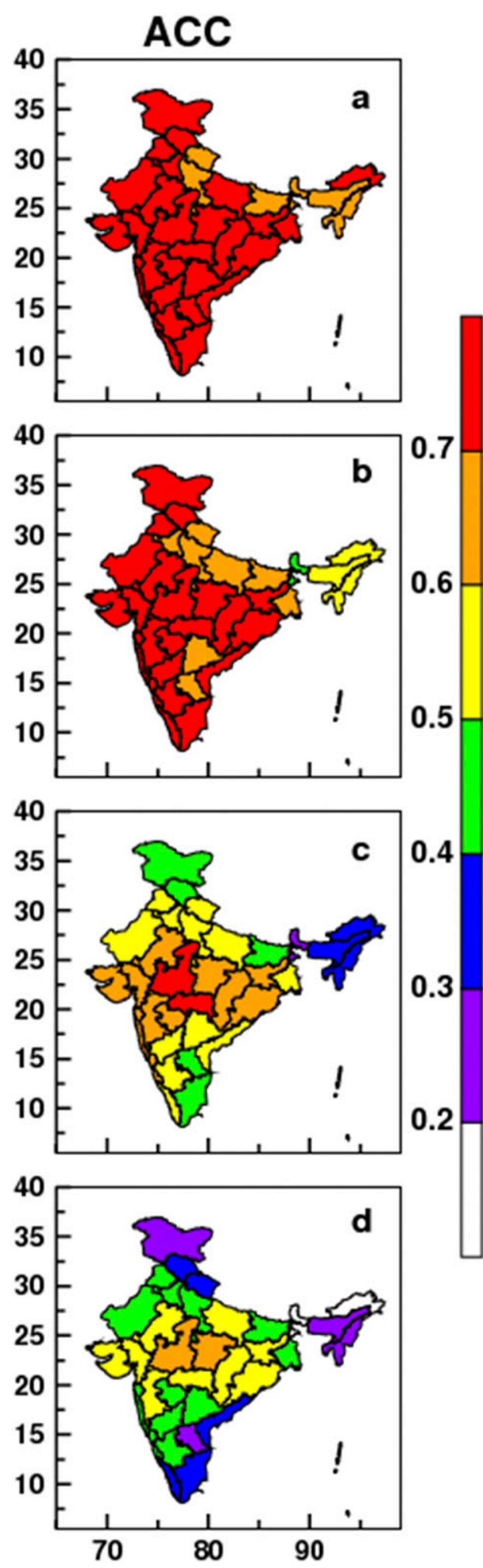

RMSS
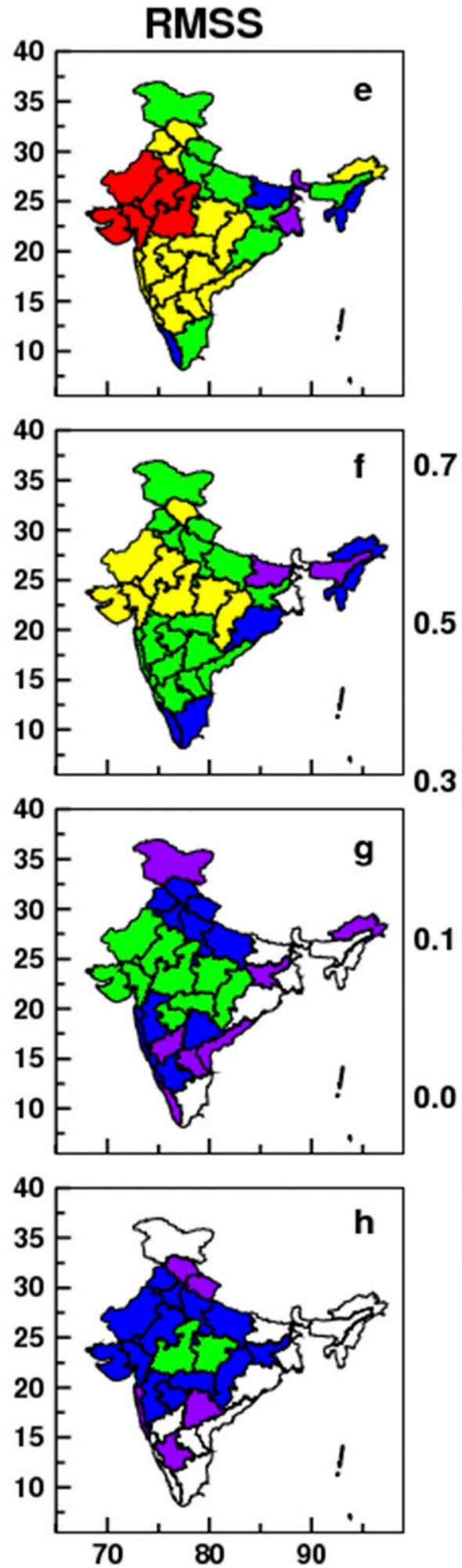

FIG. 9. As in Fig. 3, but for maximum temperature during all pentads of AMJ. 

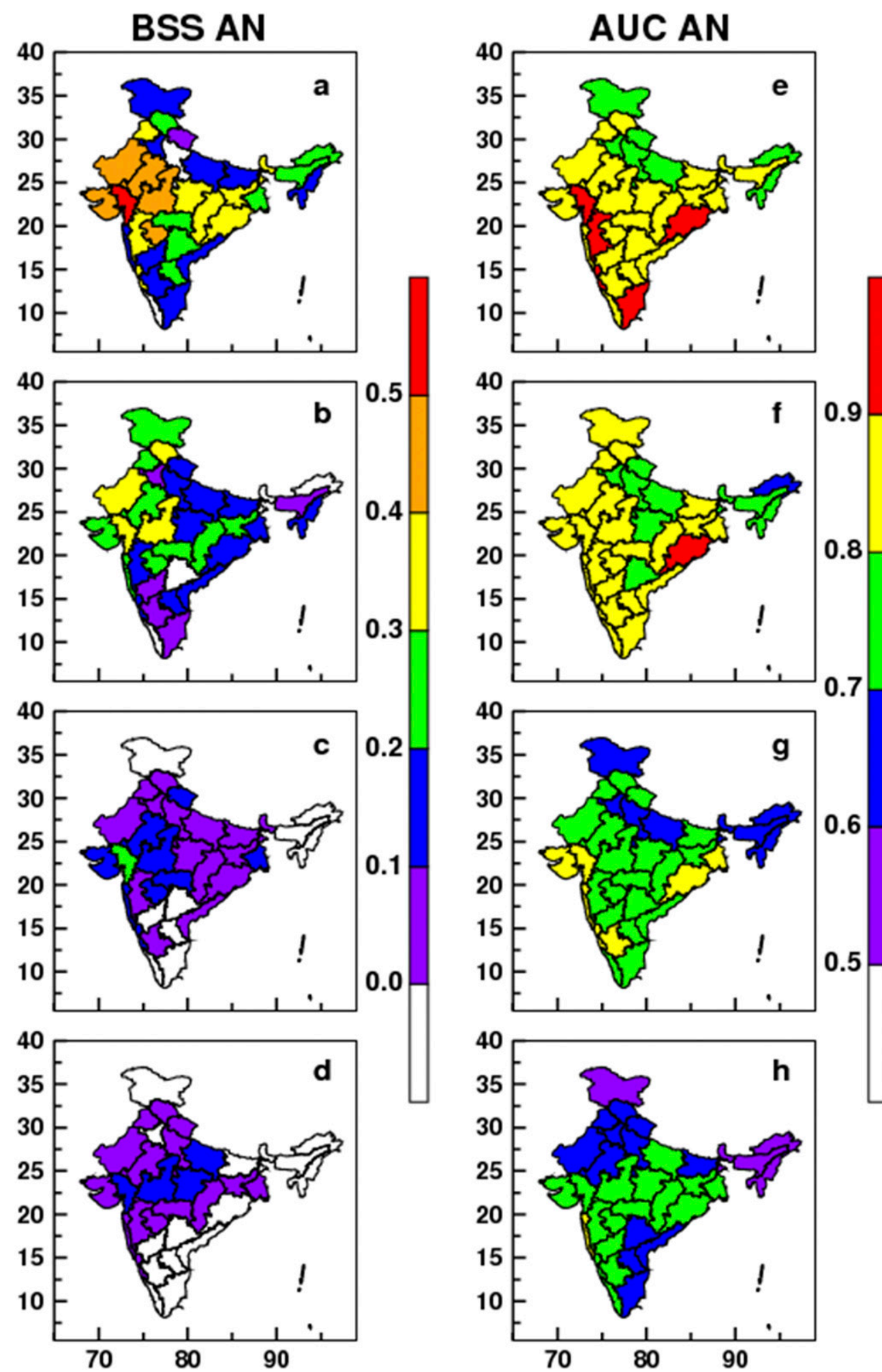

FIG. 10. Pentad-wise (P1-P4) BSS of maximum temperature in the (a)-(d) AN category for all pentads during 2001-10. (e)-(h) The AUC for the AN category of AMJ maximum temperature. 

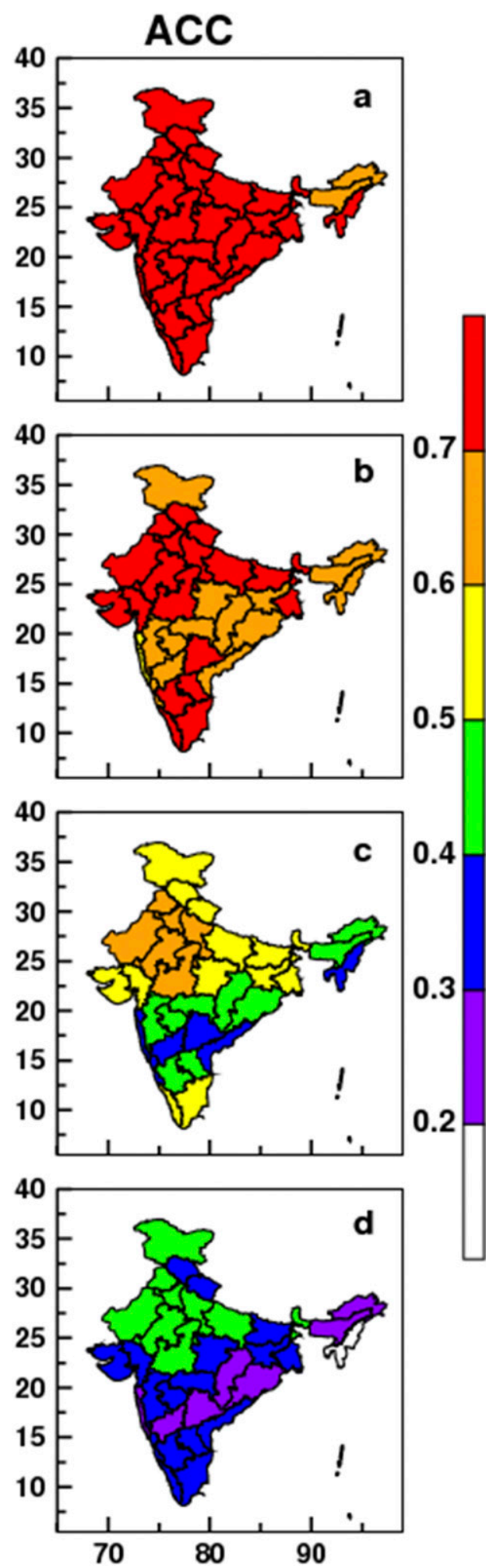

0.2
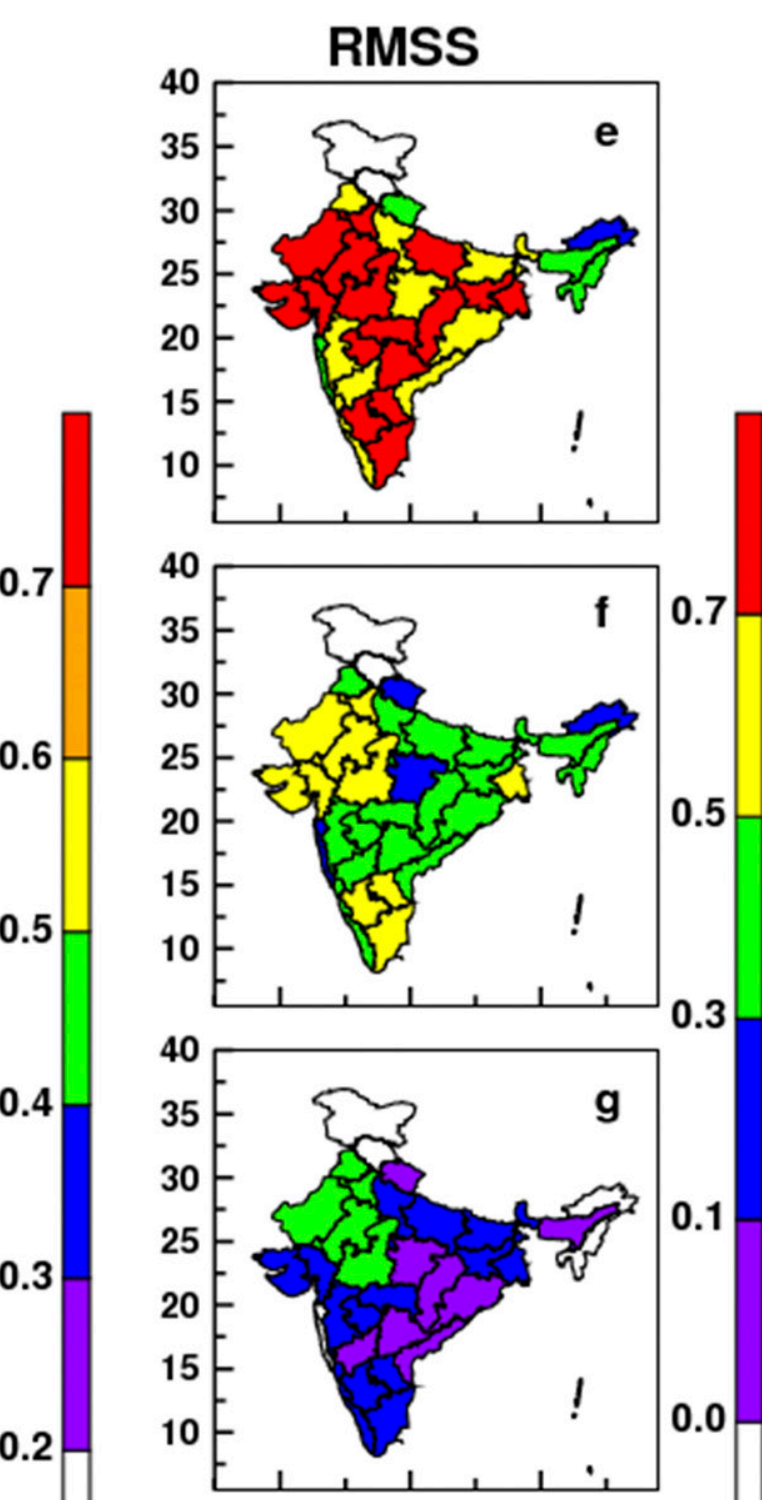

0.3

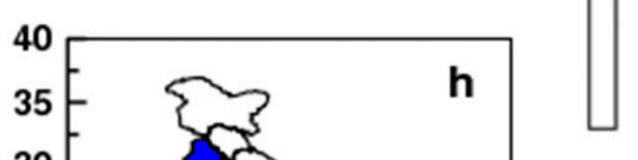

FIG. 11. As in Fig. 3, but for minimum temperature during all pentads of NDJF. 

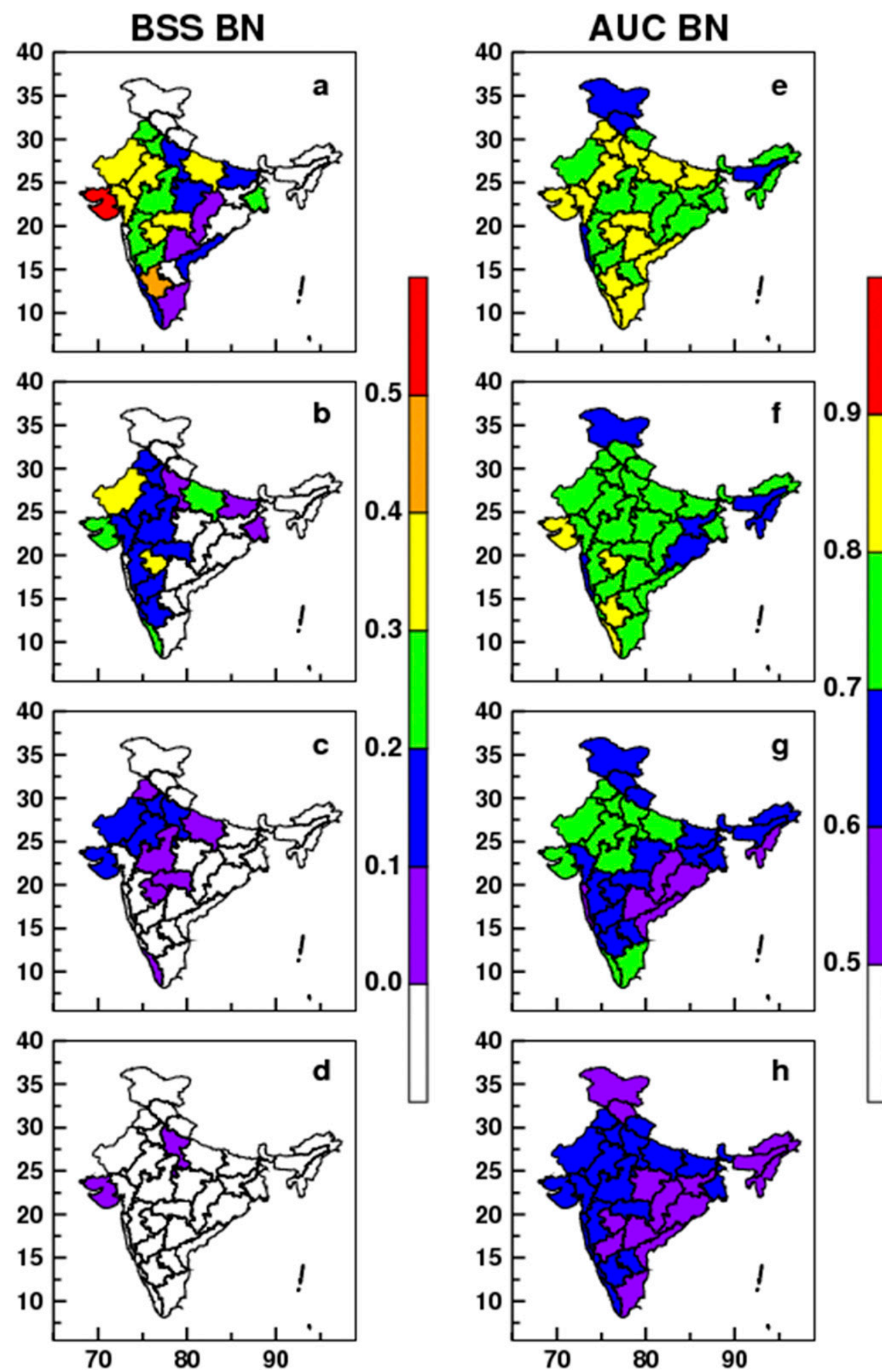

FIG. 12. As in Fig. 10, but for the BN category of minimum temperature during all pentads of NDJF. 


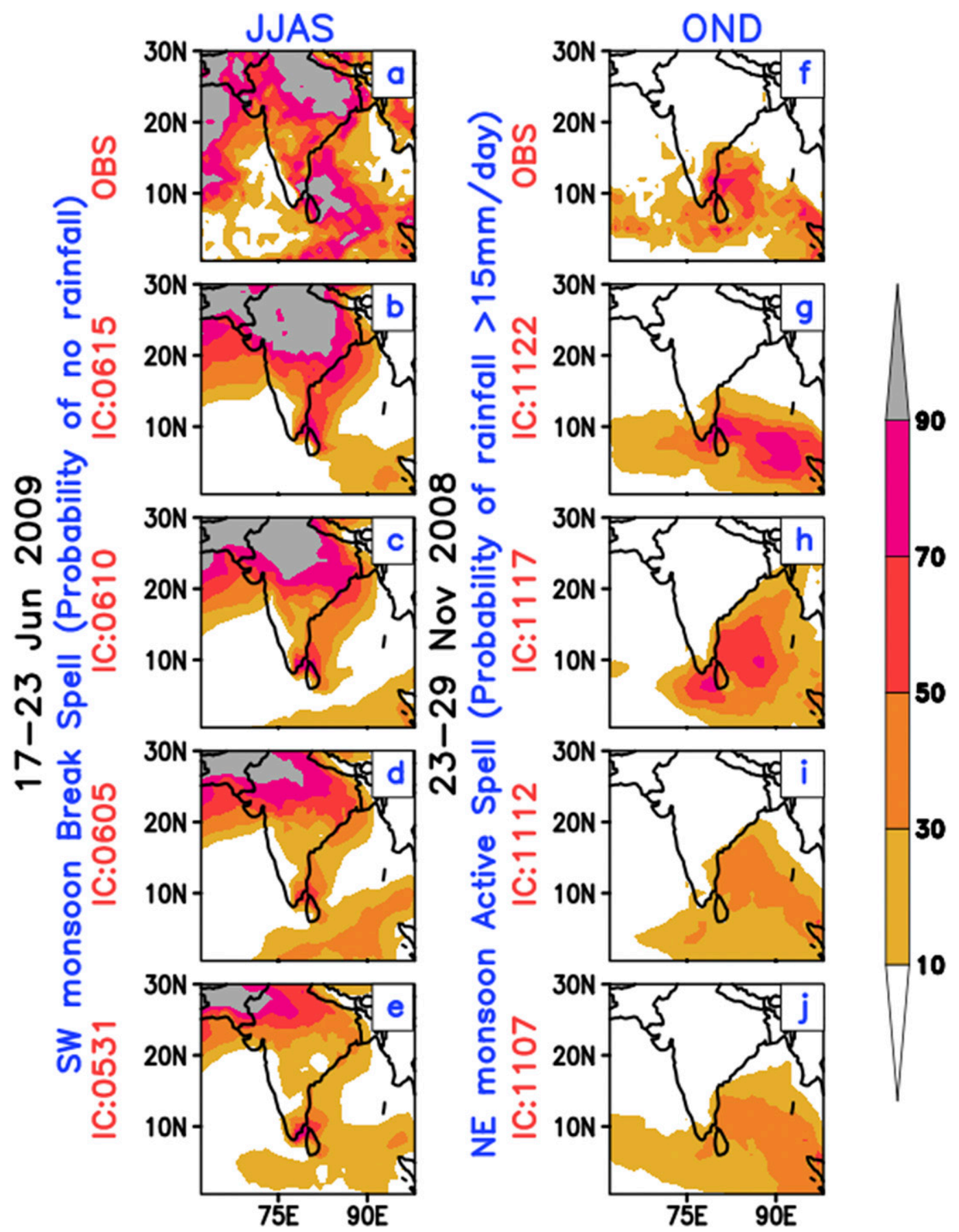

FIG. 13. Probability of occurrence of extremes (\%) in (a)-(e) JJAS and (f)-(j) OND rainfall. The observed probability is given in the first row, and the subsequent rows represent the predicted probability of the events from nearest to farthest initial conditions (ICs). The ICs are given on the left side of each subpanel.

a severe break spell occurred over most parts of the country. This spell played a major role in making 2009 a drought year. The observed probability of no rain is shown in Fig. 13a, while the MME-predicted probabilities from the nearest (15 June 2009) to the farthest initial conditions (31 May 2009) are shown in Figs. 13b-e. It is clear from the figure that the MME could successfully predict the probability of no rain during the break period from all initial conditions, although with reduced probabilities from the farthest initial conditions. 


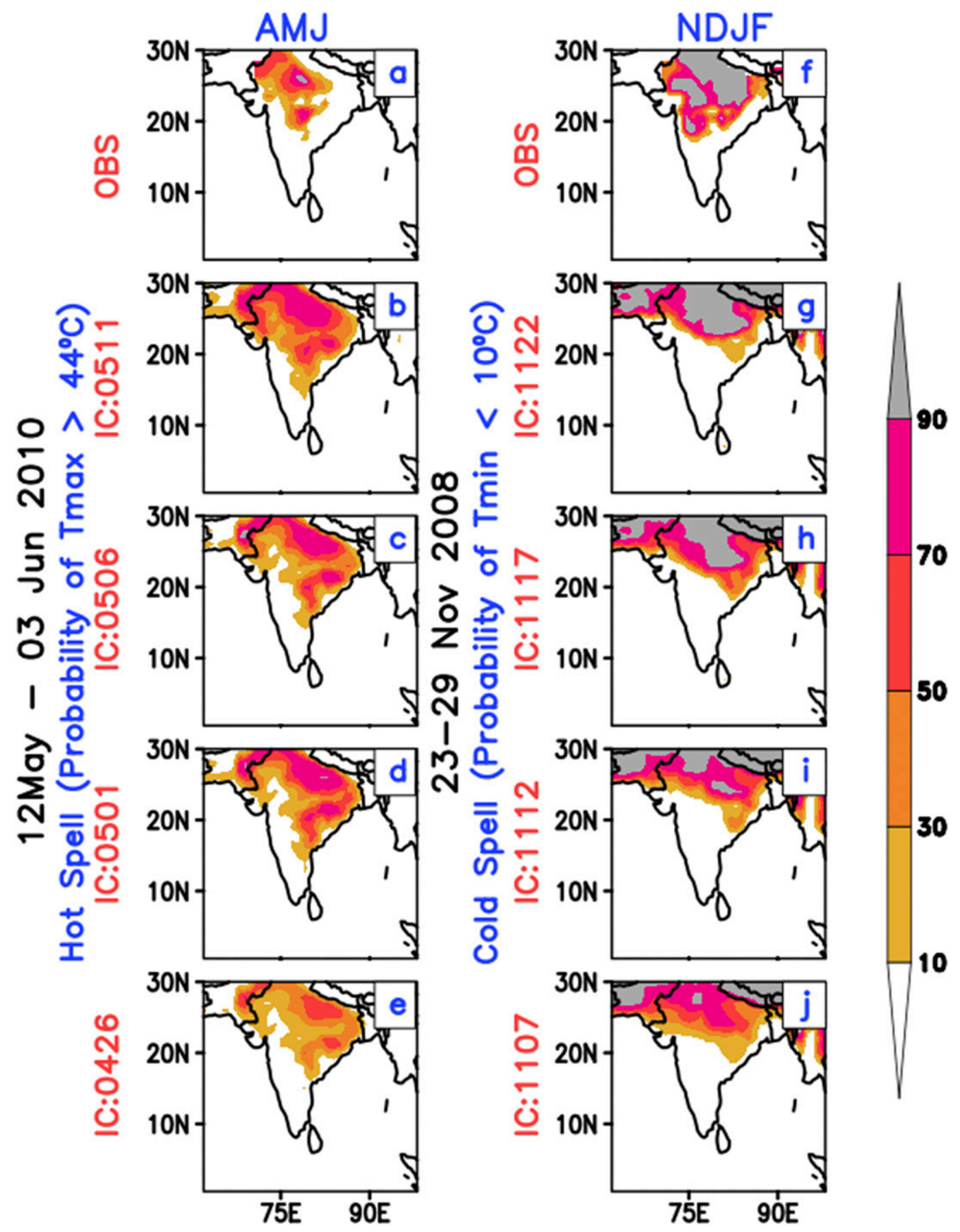

FIG. 14. As in Fig. 13, but for (a)-(e) AMJ maximum temperature and (f)-(j) NDJF minimum temperature.

As mentioned earlier, meteorological subdivisions over the southern peninsula of India experience rainfall during the OND season. Figures $13 \mathrm{f}-\mathrm{j}$ depict the observed and predicted probabilities of an active/wet spell in OND rainfall during 23-29 November 2008. Here, the probabilities of rainfall above $15 \mathrm{~mm}$ day $^{-1}$ have been calculated and plotted. Although the MME could indicate the occurrence of an active spell during the period from the nearest initial conditions, some spatial errors are noticed.

In 2010, the northwestern parts of the country experienced severe heat wave conditions during 12 May3 June. The observed as well as predicted probabilities of occurrence of the high maximum temperature values $\left(>44^{\circ} \mathrm{C}\right)$ are given in Figs. $14 \mathrm{a}-\mathrm{e}$. It is seen that the 
MME could reasonably predict the above normal temperatures during the event from almost all initial conditions. The probability of occurrence of below normal minimum temperature values $\left(<10^{\circ} \mathrm{C}\right)$ during the cold wave episode that happened from 25 to 29 January 2006 is shown in Figs. 14f-j. It is evident from the figure that the below normal temperatures were successfully predicted well in advance by the MME even from the farthest initial conditions.

Thus, we have demonstrated in this section that the CGEPS MME is skillful in predicting the extremes in rainfall and temperature.

\section{Conclusions}

There is an increasing demand for accurate extendedrange forecasts, especially over smaller spatial scales due to their widespread applications. With this increasing demand from the user community, it is necessary to document the skill of available forecasts over smaller spatial domains. This study assesses the skill of CGEPS MME, indigenously developed at the Indian Institute of Tropical Meteorology. The hindcast skill levels of rainfall during the southwest and northeast monsoon seasons and temperature during hot and cold seasons over different meteorological subdivisions are examined here, so as to understand the confidence levels associated with using these forecasts over these regions. For the assessment of deterministic forecast skill, we use ACC, RMSS, and signal-to-noise ratio; whereas for probabilistic forecasts, BSS and AUC are used.

It is found that the CGEPS MME possesses useful prediction skill for JJAS rainfall until P3 lead, and for some subdivisions, the skill extends even up to P4 lead. For OND rainfall, the deterministic and probabilistic skill scores indicate that the prediction is skillful over the relevant subdivisions, until P2 lead. The skill is reduced over longer leads, especially for the probabilistic prediction of above normal and below normal categories. During the hot season, the maximum temperature over the heat-wave-prone subdivisions have significant ACC, RMSS, BSS, and AUC values for P1-P4 pentad leads. The minimum temperature during NDJF possesses significant values of ACC, RMSS, and AUC until P4 lead. However, the BSS for the below normal category over the cold wave region is skillful only up to P3 leads. The predictability of maximum temperature (minimum temperature) is longer ( $>30$ days) during AMJ (NDJF), compared to JJAS and OND rainfall.

The ability of the CGEPS MME in predicting extremes in the JJAS/OND rainfall, AMJ maximum temperature, and NDJF minimum temperature is examined in section 3f, by selecting a few cases. It is found that MME could reasonably predict the break spell in JJAS rainfall, the active spell in OND rainfall, heat wave events in AMJ maximum temperature, and the cold wave event in NDJF minimum temperature, with sufficient lead time. It is also noted that extreme temperatures are better predicted than extremes in rainfall (which is consistent with Fig. 2 and the figures in the online supplemental material).

Thus, the present study reveals that the present CGEPS MME has noticeable skill (both probabilistic and deterministic) in predicting rainfall during the southwest and northeast monsoon seasons, maximum temperature during the summer season, and minimum temperature during the winter season over the different meteorological subdivisions of India. These results are encouraging and make us optimistic about the operational applications of this EPS at smaller spatial scales.

Acknowledgments. The research is funded by the Indian Institute of Tropical Meteorology (IITM), Pune, which is fully supported by the Ministry of Earth Sciences, Government of India. The model runs are carried out on the Aaditya High Performance Computing System installed at IITM, Pune. The authors are thankful to Dr. O. P. Sreejith and Dr. D. S. Pai of the India Meteorological Department for providing the subdivisional mask files, and Dr. J. V. Revadekar of IITM for her guidance in generating the figure files using Xmgrace.

\section{REFERENCES}

Abhilash, S., A. K. Sahai, N. Borah, R. Chattopadhyay, S. Joseph, S. Sharmila, S. De, and B. N. Goswami, 2014a: Does bias correction in the forecasted SST improve the extended range prediction skill of active-break spells of Indian summer monsoon rainfall? Atmos. Sci. Lett., 15, 114-119, https:// doi.org/10.1002/asl2.477.

$-,-,-,-,-\longrightarrow,-,-$, and A. Kumar, 2014b: Prediction and monitoring of monsoon intraseasonal oscillations over Indian monsoon region in an ensemble prediction system using CFSv2. Climate Dyn., 42, 2801-2815, https://doi.org/10.1007/s00382-013-2045-9.

,,-- S. Pattnaik, B. N. Goswami, and A. Kumar, 2014c: Extended range prediction of active-break spells of Indian summer monsoon rainfall using an ensemble prediction system in NCEP Climate Forecast System. Int. J. Climatol., 34, 98-113, https://doi.org/10.1002/joc.3668.

_ , and Coauthors, 2015a: Better spread-error relationship in a multimodel ensemble prediction system. Bull. Amer. Meteor. Soc., 96, 1228-1229, https://doi.org/10.1175/1520-0477-96.8.1221.

_ , and Coauthors, 2015b: Improved spread-error relationship and probabilistic prediction from the CFS-based Grand Ensemble Prediction System. J. Appl. Meteor. Climatol., 54, 1569-1578, https://doi.org/10.1175/JAMC-D-14-0200.1.

Hamill, T. M., and J. Juras, 2006: Measuring forecast skill: Is it real skill or is it the varying climatology? Quart. J. Roy. Meteor. Soc., 132, 2905-2923, https://doi.org/10.1256/qj.06.25. 
Han, J., and H.-L. Pan, 2011: Revision of convection and vertical diffusion schemes in the NCEP Global Forecast System. Wea. Forecasting, 26, 520-533, https://doi.org/10.1175/WAF-D-1005038.1.

Joseph, S., and Coauthors, 2015: North Indian heavy rainfall event during June 2013: Diagnostics and extended range prediction. Climate Dyn., 44, 2049-2065, https://doi.org/10.1007/s00382014-2291-5.

Kharin, V. V., and F. W. Zwiers, 2003: On the ROC score of probability forecasts. J. Climate, 16, 4145-4150, https://doi.org/ 10.1175/1520-0442(2003)016<4145:OTRSOP $>2.0$.CO;2.

Kripalani, R. H., and P. Kumar, 2004: Northeast monsoon rainfall variability over south peninsular Indian vis-a-vis the Indian Ocean dipole mode. Int. J. Climatol., 24, 1267-1282, https:// doi.org/10.1002/joc.1071.

Mohanty, U. C., and Coauthors, 2013: Real-time experimental extended range forecast system for Indian summer monsoon rainfall: A case study for monsoon 2011. Curr. Sci., 104, $856-870$.

Pan, H. L., and W. S. Wu, 1995: Implementing a mass flux convective parameterization package for the NMC mediumrange forecast model. NMC Office Note 409, 43 pp., http:// www2.mmm.ucar.edu/wrf/users/phys_refs/CU_PHYS/Old_SAS.pdf.

Pattanaik, D. R., 2014: Meteorological subdivisional-level extended range forecast over India during southwest monsoon 2012. Meteor. Atmos. Phys., 124, 167-182, https://doi.org/ 10.1007/s00703-014-0308-6.

Rajeevan, M., J. Bhate, J. D. Kale, and B. Lal, 2006: High resolution daily gridded rainfall data for the Indian region: Analysis of break and active monsoon spells. Curr. Sci., 91, 296-306.

, S. Gadgil, and J. Bhate, 2010: Active and break spells of the Indian summer monsoon. J. Earth Syst. Sci., 119, 229-247, https://doi.org/10.1007/s12040-010-0019-4.
Saha, S., and Coauthors, 2014: The NCEP Climate Forecast System version 2. J. Climate, 27, 2185-2208, https://doi.org/10.1175/ JCLI-D-12-00823.1.

Sahai, A. K., and Coauthors, 2013: Simulation and extended range prediction of monsoon intraseasonal oscillations in NCEP CFS/GFS version 2 framework. Curr. Sci., 104, 1394-1408.

—, S. Abhilash, R. Chattopadhyay, N. Borah, S. Joseph, S. Sharmila, and M. Rajeevan, 2015a: High-resolution operational monsoon forecasts: An objective assessment. Climate Dyn., 44, 3129-3140, https://doi.org/10.1007/s00382014-2210-9.

_- R. Chattopadhyay, S. Joseph, R. Mandal, A. Dey, S. Abhilash, R. P. M. Krishna, and N. Borah, 2015b: Real-time performance of a multi-model ensemble based extended range forecast system in predicting the 2014 monsoon season based on NCEPCFSv2. Curr. Sci., 109, 1802-1813.

Saseendran, S. A., S. V. Singh, L. S. Rathore, and S. Das, 2002: Characterization of weekly cumulative rainfall forecasts over meteorological subdivisions of India using a GCM. Wea. Forecasting, 17, 832-844, https://doi.org/10.1175/1520-0434(2002) 017<0832:COWCRF $>2.0 . \mathrm{CO} ; 2$.

Shukla, J., and D. S. Gutzler, 1983: Interannual variability and predictability of $500 \mathrm{mb}$ geopotential heights over the Northern Hemisphere. Mon. Wea. Rev., 111, 1273-1279, https://doi.org/10.1175/1520-0493(1983)111<1273:IVAPOM> 2.0.CO;2.

Srivastava, A. K., M. Rajeevan, and S. R. Kshirsagar, 2008: Development of a high resolution daily gridded temperature data set (1969-2005) for the Indian region. NCC Research Rep. 8, India Meteorological Department, 15 pp., http://imdpune. gov.in/Clim_Pred_LRF_New/Reports/NCCResearchReports/ research_report_8.pdf.

Wilks, D. S., 2011: Statistical Methods in the Atmospheric Sciences. 3rd ed. Elsevier, 676. 